\title{
Physical Activity Level of Post-menopausal Women with Low Bone Mineral Density
}

\section{Nível de atividade física de mulheres menopausadas com baixa densidade mineral óssea} \author{
José Eduardo Corrente ${ }^{4}$ Gláucia Maria Ferreira da Silva Mazeto ${ }^{2}$ \\ ${ }^{1}$ Department of Physical Education, Faculdade de Educação Física de \\ Barra Bonita (Faefi), Barra Bonita, SP, Brazil \\ 2 Department of Internal Medicine, Faculdade de Medicina de \\ Botucatu, Universidade Estadual Paulista - Unesp, Botucatu, SP, \\ Brazil \\ ${ }^{3}$ Department of Gynecology and Obstetrics, Faculdade de Medicina \\ de Botucatu, Universidade Estadual Paulista - Unesp, Botucatu, SP, \\ Brazil \\ ${ }^{4}$ Department of Biostatistics, Instituto de Biociências, Universidade \\ Estadual Paulista - Unesp, Botucatu, SP, Brazil
}

Glauber Dallanezi ${ }^{1}$ Beatriz Funayama Alvarenga Freire ${ }^{2}$ Eliana Aguiar Petri Nahás ${ }^{3}$ Jorge Nahás-Neto ${ }^{3}$

Rev Bras Ginecol Obstet 2016;38:225-230.
Address for correspondence Glaucia M. F. S. Mazeto, MD, PhD, Departmento de Clínica Médica, Faculdade de Medicina de Botucatu, Universidade Estadual Paulista, 18618-000, Botucatu, SP, Brazil (e-mail: gmazeto@fmb.unesp.br).

\begin{abstract}
Keywords

- osteoporosis

- metabolic bone diseases

- exercise

- questionnaires

Introduction Proper physical activity is related to the prevention and the treatment of osteoporosis.

Purpose To assess the level of physical activity (PA) in post-menopausal women with low bone mineral density (BMD).

Methods This cross-sectional clinical study included 123 post-menopausal women. The inclusion criteria were: age of $\geq 45$ years with last menses at least 12 months prior to the initiation of the study, and bone density scan (BDS) values measured over the preceding 12 months. Women with severe osteoarthritis were excluded. Women were allocated into three groups, according to BMD measured by BDS [osteoporosis (OP; 54 women), osteopenia (35 women), and normal bone density (NBD; 35 women)], and compared for general, clinical, and anthropometric data, and for PA level. The latter was assessed using the International Physical Activity Questionnaire (IPAQ), in metabolic equivalent of task (MET) units. Participants were classified as sedentary, active or very active. Quantitative variables were compared using ANOVA followed by Tukey's test. Associations between qualitative variables were tested by Chi-square $\left(x^{2}\right)$ or Fisher's exact test. In order to check for differences among groups and IPAQ domains, a generalized linear model with Gamma distribution was adjusted for values in METs.

Results The OP group differed from the NBD group regarding age $(61.8 \pm 10.1$ and $52.9 \pm 5.4$ years), percentage of participants with self-declared white ethnicity (43.9 and $28.0 \%$ ), body mass index (BMI $-25.7 \pm 5.4$ and $\left.30.9 \pm 5.1 \mathrm{~kg} / \mathrm{m}^{2}\right)$, and time since menopause $(15.5 \pm 7.5$ and $5.8 \pm 4.5$ years $)$. Smoking rates were higher in the OP
\end{abstract}

received July 7, 2015 accepted March 21, 2016 published online May 4, 2016
DOI http://dx.doi.org/ 10.1055/s-0036-1583757. ISSN $0100-7203$.
Copyright $@ 2016$ by Thieme Publicações License terms

Ltda, Rio de Janeiro, Brazil 
Resumo

Palavras-chave

- osteoporose

- doenças ósseas metabólicas

- exercício

- questionários
(55.6\%) and NBD groups (33.3\%) than in the osteopenia group (11.1\%). Within the OP group, the rate of subjects with sedentary lifestyles was higher (42.6\%), and time spent sitting was greater ( $344.3 \pm 204.8 \mathrm{METs})$ than in the groups with osteopenia $(20.0 \%$ and $300.9 \pm 230.6 \mathrm{METs})$ and NBD (17.7\% and $303.2 \pm 187.9 \mathrm{METs})$.

Conclusions The rate of sedentary lifestyles was higher in post-menopausal women with OP than in those with either osteopenia or NBD. In order to change this physical inactivity profile, strategies should be created to address this group of patients.

Introdução Atividade física adequada está relacionada com a prevenção e o tratamento da osteoporose.

Objetivo Avaliar o nível de atividade física em mulheres na pós-menopausa com baixa densidade mineral óssea (DMO).

Métodos Este estudo clínico transversal incluiu 123 mulheres na pós-menopausa. Os critérios de inclusão foram idade $\geq 45$ anos, com última menstruação pelo menos 12 meses antes do início do estudo, e DMO medida nos últimos 12 meses. Foram excluídas mulheres com osteoartrite grave. As mulheres foram divididas em três grupos, de acordo com DMO medida por densitometria óssea [osteoporose (OP; 54 mulheres), osteopenia (35 mulheres) e DMO normal (NBD; 35 mulheres)], e comparadas com dados gerais, clínicos e antropométricos, e quanto ao nível de atividade física. Este último foi avaliado pelo International Physical Activity Questionnaire (IPAQ), em unidades de metabolic equivalent of task (METs). As participantes foram classificadas como sedentárias, ativas ou muito ativas. As variáveis quantitativas foram comparadas por ANOVA seguida pelo teste de Tukey. As associações entre as variáveis qualitativas foram testadas por Qui-quadrado (X2) ou exato de Fisher. Para verificar diferenças entre os grupos e domínios do IPAQ, um modelo linear generalizado com distribuição Gama foi ajustado para os valores em METs.

Resultados O grupo OP diferiu do NBD quanto à idade $(61,8 \pm 10,1$ e $52,9 \pm 5,4$ anos), porcentagem de etnia autorrelatada branca (43,9 e $28,0 \%$ ), índice de massa corporal $\left(25,7 \pm 5,4\right.$ e $\left.30,9 \pm 5,1 \mathrm{~kg} / \mathrm{m}^{2}\right)$ e tempo da menopausa $(15,5 \pm 7,5$ e $5,8 \pm 4,5$ anos). As taxas de tabagismo foram maiores nos grupos com OP $(55,6 \%)$ e NBD $(33,3 \%)$ do que no com osteopenia $(11,1 \%)$. No grupo com OP, sedentarismo $(42,6 \%)$ e tempo gasto sentado foram maiores (344,3 $\pm 204.8 \mathrm{METs}$ ) do que nos com osteopenia ( $20,0 \%$ e $300,9 \pm 230,6$ METs) e NBD (17,7\% e 303,2 $\pm 187,9$ METs).

Conclusões $\mathrm{O}$ sedentarismo foi maior em mulheres na pós-menopausa com osteoporose do que naquelas com osteopenia ou NBD. Estratégias devem ser criadas para alterar este perfil de inatividade física neste grupo de pacientes.

\section{Introduction}

Osteoporosis (OP) is a condition of high prevalence that affects millions of people worldwide. Clinical presentation can be quite variable, ranging from asymptomatic bone loss to severe fractures (especially of the femur and radius) caused by falls. ${ }^{1}$ Elderly people, particularly women after menopause, are at a greater risk of developing OP. ${ }^{2}$

OP treatment includes correction of nutritional deficiencies, particularly of calcium and vitamin $\mathrm{D}$, prescription of medicines ${ }^{3}$ and physical exercise. Regular physical activity (PA) can prevent bone mass loss, ${ }^{4,5}$ and some types of physical exercises improve muscle strength and balance, thereby reducing the frequency of falls and subsequent fractures, especially among the elderly. ${ }^{6}$ Nonetheless, the prevalence of physical inactivity is highest precisely in women and in elderly individuals, ${ }^{7}$ which are at an increased risk for OP. In fact, the level of PA is one of the most prevalent indicators of frailty, which leads to falls, fractures, hospitalization, disabilities and death. ${ }^{8}$ Thus, this study aimed to assess the level of PA in post-menopausal women with low bone mineral density.

\section{Patients and Methods}

This cross-sectional analytic clinical study included 123 women attending an outpatient clinic for calcium disorders 
and climacteric \& menopause. The non-probabilistic voluntary sample was estimated assuming a loss of $20 \%$. The inclusion criteria were: participants must have an age of $\geq 45$ years, with last menses at least 12 months prior to the initiation of the study, and bone density scan (BDS) values measured over the preceding 12 months. Women with severe osteoarthritis were excluded. Participants were allocated into three groups: OP as diagnosed by BDS (54 women); osteopenia (35 women); and normal bone density (NBD, 34 women). The study was performed according to the Declaration of Helsinki, which was reviewed in 2008 and approved by the Institutional Research Ethics Committee (\#;318/2006). Written informed consent was obtained from all participants.

Interviews with all 123 study participants were used for data collection. The data collected included age, time since menopause, ethnicity, smoking status (if patients are currently smoking, regardless of the number of cigarettes per day), use of hormone replacement therapy (HRT), history of bone pain or fractures, chronic diseases (such as hypertension and diabetes), and chronic use of medicines. PA was assessed using the International Physical Activity Questionnaire (IPAQ)-Long Form, version 8, validated for the Brazilian population, ${ }^{9}$ which corresponds to the pedometer when applied to post-menopausal women with OP. ${ }^{10}$ The IPAQLong Form covers five domains: work-related PA; transportation-related PA; domestic PA; recreation, sports, and leisure-time PA, and time spent sitting. IPAQ total and domainspecific continuous scores were expressed as metabolic equivalent units (METs). Participants were classified into three categories: sedentary, active, and very active. ${ }^{11,12}$ All interviews were handled by the same interviewer after routine consultation in the outpatient services.

The anthropometric data collected included body weight, height and body mass index (BMI). ${ }^{2}$ Body weight was measured using a platform scale (150 kg maximum capacity and $0.1 \mathrm{~kg}$ precision) with participants in light clothing and without shoes; height was measured to the nearest $0.1 \mathrm{~cm}$ with a portable wall anthropometer.
Bone mineral density (BMD) was assessed based on BDS performed over the preceding 12 months at the Radiology Unit of Botucatu Medical School. BMD was measured by dual-energy X-ray absorptiometry (DXA) scans of the lumbar spine (LS) and the femoral neck (FN) (Hologic QDR-2000, Waltham, MA, USA). DXA coefficients of variation during the examination period were below $2 \%$. BMD values were reported using T-scores, which is the patient's BMD compared with what is normally expected in a healthy young adult of the same sex, the difference being expressed as a standard deviation (SD) score. Thus, according to BMD, participants were classified as normal ( $\mathrm{T}$-score $\geq-1.0 \mathrm{SD}$ ); osteopenic ( $\mathrm{T}$ score $=-1.0-2.4 \mathrm{SD})$; or osteoporotic $(\mathrm{T}$-score $\leq-2.5 \mathrm{SD}) .^{3}$

\section{Statistical Analysis}

Descriptive statistics was used to establish the main characteristics of the study sample. Quantitative variables were expressed as mean \pm SD. Qualitative variables were presented as frequencies or percentages. IPAQ domains, continuous scores in METs-minutes and the percentage of participants were compared among groups. The percentage of participants in each IPAQ physical activity class was also compared. Quantitative variables were compared using ANOVA followed by Tukey's test. Associations between qualitative variables were tested by Chi-square ( $\mathrm{X}^{2}$ ) or Fisher's exact test, when applicable. To check differences among groups and IPAQ domains, a generalized linear model with Gamma distribution was adjusted for values in METs due to the non-normality of the data. For multiple comparisons, the DIFF option on PROCGENMOD SAS for Windows (v. 9.1.3; Cary, NC, USA) was used.

\section{Results}

On average, age and time since menopause were significantly higher in women with osteoporosis when compared with the remaining groups. The NBD and osteopenia groups showed significantly higher mean BMI than the OP group. As expected, BMD values in the NBD group were higher than in the osteopenia and OP groups (-Table 1). The percentage of

Table 1 Clinical and densitometric parameters* in the 123 post-menopausal participants per group

\begin{tabular}{|c|c|c|c|}
\hline Variables & NBD $(n=34)$ & Osteopenia $(n=35)$ & $\mathrm{OP}(n=54)$ \\
\hline Age (years) & $52.9 \pm 5.4^{a}$ & $56.7 \pm 7.2^{a}$ & $61.8 \pm 10.1^{b}$ \\
\hline Time since menopause (years) & $5.8 \pm 4.5^{a}$ & $8.4 \pm 5.9^{a}$ & $15.5 \pm 7.5^{b}$ \\
\hline BMI $\left(\mathrm{kg} / \mathrm{m}^{2}\right)$ & $30.9 \pm 5.1^{b}$ & $28.6 \pm 3.7^{b}$ & $25.7 \pm 5.4^{a}$ \\
\hline BMD FN $\left(\mathrm{g} / \mathrm{cm}^{2}\right)$ & $0.9 \pm 0.1^{c}$ & $0.8 \pm 0.1^{b}$ & $0.6 \pm 0.1^{\mathrm{a}}$ \\
\hline $\operatorname{BMD~LS}\left(\mathrm{g} / \mathrm{cm}^{2}\right)$ & $1.1 \pm 0.2^{c}$ & $1.0 \pm 0.1^{b}$ & $0.8 \pm 0.1^{a}$ \\
\hline BMD FN (SD) & $0.2 \pm 0.9^{c}$ & $-1.5 \pm 1.7^{b}$ & $-2,8 \pm 0.8^{a}$ \\
\hline BMD LS (SD) & $0.2 \pm 1.1^{c}$ & $-1.2 \pm 1.0^{b}$ & $-2.7 \pm 1.1^{a}$ \\
\hline
\end{tabular}

Abbreviations: NBD, normal bone density; OP, osteoporosis; BMI, body mass index; BMD, bone mineral density; FN, femoral neck; LS, lumbar spine; SD, standard deviation.

Notes: *Values expressed as mean \pm standard deviation.

a,b,c Different letters indicate significant differences $(c>b>a)$ and a same letter indicates no difference in mean between groups $(p>0.05)$

(ANOVA followed by Tukey's test). 
Table 2 Distribution of the 123 post-menopausal women according to International Physical Activity Questionnaire (IPAQ) domains / classes and study group

\begin{tabular}{|l|l|l|l|l|}
\hline IPAQ domains & $\begin{array}{l}\text { NBD } \\
\mathbf{n}(\%)\end{array}$ & $\begin{array}{l}\text { Osteopenia } \\
\mathbf{n}(\%)\end{array}$ & $\begin{array}{l}\text { OP } \\
\mathbf{n}(\%)\end{array}$ & $\boldsymbol{p}^{*}$ value \\
\hline Work-related PA & $12(35.3)^{\mathrm{a}}$ & $11(31.4)^{\mathrm{a}}$ & $14(25.9)^{\mathrm{a}}$ & 0.636 \\
\hline Transportation-related PA & $27(79.4)^{\mathrm{a}}$ & $28(80.0)^{\mathrm{a}}$ & $42(77.8)^{\mathrm{a}}$ & 0.965 \\
\hline Domestic PA & $33(97.1)^{\mathrm{a}}$ & $33(94.3)^{\mathrm{a}}$ & $48(88.9)^{\mathrm{a}}$ & 0.326 \\
\hline Recreation, sports, and leisure-time PA & $18(52.9)^{\mathrm{a}}$ & $20(57.1)^{\mathrm{a}}$ & $22(40.7)^{\mathrm{a}}$ & 0.271 \\
\hline Time spent sitting & $31(91.2)^{\mathrm{a}}$ & $33(94.3)^{\mathrm{a}}$ & $50(92.59)^{\mathrm{a}}$ & 0.884 \\
\hline IPAQ classes & & & & \\
\hline Sedentary & $6(17.6)^{\mathrm{a}}$ & $7(20.0)^{\mathrm{a}}$ & $23(42.6)^{\mathrm{b}}$ & 0.016 \\
\hline Active & $7(20.6)^{\mathrm{a}}$ & $8(22.9)^{\mathrm{a}}$ & $11(20.4)^{\mathrm{a}}$ & 0.957 \\
\hline Very active & $21(61.8)^{\mathrm{b}}$ & $20(57.1)^{\mathrm{b}}$ & $20(37.0)^{\mathrm{a}}$ & 0.045 \\
\hline
\end{tabular}

Abbreviations: NBD, normal bone density; OP, osteoporosis; PA, physical activity.

Notes: Values expressed as numbers $(n)$ and percentages between parentheses.

* Significant difference if $p>0.05$ (Chi-square test).

a,b Different letters $(b>a)$ indicate significant differences between groups, and a same letter indicates no difference.

participants self-declared as being of white ethnicity was highest in the OP group (43.9\% against $28.1 \%$ for the osteopenia group, and $28.0 \%$ for the NBD group; $p<0.05$ ). Smoking was less frequent among women with osteopenia (11.1\%) than among those with OP (55.6\%) and NBD (33.3\%) $(p<0.05)$. None of the patients had a history of bone pain or fractures. Medicines for chronic diseases were used by $72.7 \%$ of the women with OP, while only by $24.2 \%$ and $3.0 \%$ of the participants with osteopenia and NBD, respectively $(p<0.0001)$. No difference in the percentage of HRT users was observed among groups (NBD group: 43.8\%; osteopenia group: $34.4 \%$; OP group: $21.9 \% ; p>0.05$ ). In the OP group, $45.5 \%$ of participants used alendronate, while $41.8 \%$ used calcitonin. In the osteopenia group, only $8.6 \%$ used alendronate. No woman with NBD used either calcitonin or alendronate (data not shown).

IPAQ results showed that when compared with the other groups, the OP group had the highest rate of sedentary lifestyles $(p>0.05)$ and the lowest percentage of very active women $(p<0.05)$ ( - Table 2 ).
No difference in participant distribution according to the PA developed in each domain was observed among groups (-Table 2). Time spent sitting in METs was highest in the OP group ( - Table 3 ). There was no difference among groups regarding the other domains assessed.

\section{Discussion}

Osteoporosis is a silent disease. Women with low bone mass do not usually complain or experience changes in quality of life as long as they have no fractures. ${ }^{13}$ In post-menopausal women, the therapeutic approach to low BMD usually involves the use of medicines. However, long-term compliance to this kind of treatment is low, as patients are usually asymptomatic. ${ }^{14}$ Since PA has been related to increased BMD, ${ }^{15}$ osteoporosis treatment should involve lifestyle changes, including regular PA, which is associated with better health and a reduced rate of falls, particularly among the elderly. ${ }^{6}$

In this study, the level of PA was assessed by IPAQ in the osteoporosis and osteopenia groups, which were then

Table 3 International Physical Activity Questionnaire (IPAQ)* scores expressed as metabolic equivalent of task units (METsminutes/week) per group of post-menopausal women

\begin{tabular}{|l|l|l|l|}
\hline IPAQ domains & $\begin{array}{l}\text { NBD } \\
(\boldsymbol{n}=\mathbf{3 4 )}\end{array}$ & $\begin{array}{l}\text { Osteopenia } \\
(\boldsymbol{n}=35)\end{array}$ & $\begin{array}{l}\text { OP } \\
(\boldsymbol{n}=\mathbf{5 4})\end{array}$ \\
\hline Work-related PA & $1710.41 \pm 3444.53^{\mathrm{a}}$ & $1235.89 \pm 2595.07^{\mathrm{a}}$ & $2104.54 \pm 5619.89^{\mathrm{a}}$ \\
\hline Transportation-related PA & $339.71 \pm 320.08^{\mathrm{a}}$ & $351.94 \pm 603.87^{\mathrm{a}}$ & $376.58 \pm 555.85^{\mathrm{a}}$ \\
\hline Domestic PA & $1880.37 \pm 1632.49^{\mathrm{a}}$ & $2510.79 \pm 3860.40^{\mathrm{a}}$ & $1808.52 \pm 2269.53^{\mathrm{a}}$ \\
\hline Recreation, sports, and Leisure-time PA & $405.24 \pm 711.54^{\mathrm{a}}$ & $444.24 \pm 721.46^{\mathrm{a}}$ & $326.65 \pm 488.75^{\mathrm{a}}$ \\
\hline Time spent sitting & $303.24 \pm 187.93^{\mathrm{a}}$ & $300.86 \pm 230.58^{\mathrm{a}}$ & $344.28 \pm 204.85^{\mathrm{b}}$ \\
\hline
\end{tabular}

Abbreviations: NBD, normal bone density; OP, osteoporosis; PA, physical activity.

Notes: *Values expressed as mean \pm standard deviation.

${ }^{a, b}$ Different letters $(b>a)$ indicate significant differences among groups, and a same letter indicates no difference $(p>0.05)$ (linear model with Gamma distribution). 
compared with the NBD group. Most of the participants in the OP group were sedentary, while higher rates of very active women were observed in the NBD and osteopenia groups. In fact, higher BMD is reported in more active subjects, and other studies conducted in different regions of Brazil reported high rates of sedentary lifestyles in the elderly population. ${ }^{16,17}$ In these studies, the association of age and sedentary lifestyles with osteoporosis is largely reported, and the cause and effect relationship is widely discussed. ${ }^{16,17}$ However, other authors have observed that, in healthy elderly post-menopausal women, PA level, habitual PA, maximum strength of the legs and aerobic capacity have no influence on BMD. ${ }^{18}$ A study conducted with Chinese post-menopausal women using the IPAQ noted that only $7 \%$ of them had low PA levels. However, while moderate PA levels were beneficial for bone health, low levels have not been found to be helpful in preventing a decline in BMD. ${ }^{19}$

Energy expenditure with PA evaluated by IPAQ domains did not differ among groups. However, time spent sitting was greater in the OP group, which is consistent with sedentary lifestyles. Supporting this finding, no difference among groups was observed regarding the percentage of participants engaged in the activities related to the different IPAQ domains. Nonetheless, the rates observed in the NBD and osteopenia groups were more impressive in all physical activity domains. A study conducted in the southern region of Brazil with women with an average age of 67 found lower energy expenditure (in METs) for the IPAQ domains related to more vigorous activities. ${ }^{20}$ In contrast, researchers observed higher expenditure in the "domestic PA" domain. ${ }^{20} \mathrm{MET}$ values observed in our study for the "work-related PA" domain were higher, and those for the "domestic PA" domain were lower than the values found in that study. ${ }^{20}$ It is noteworthy that most women with OP reported having no jobs outside their home. People who work outside of their homes often choose to walk to work as a way to introduce some exercise in their daily routine.

Several factors may have impacted the willingness and ability to practice PA in the OP group. First, the NBD group, despite being similar to the osteopenia group, differed from the OP group regarding age, self-declared ethnicity, BMI and time since menopause. This finding was expected, since these parameters represent known clinical risk factors for osteoporosis, and are related to the pathophysiology of the disease. ${ }^{2}$ Age, overweightness and hypoestrogenism can affect not only BMD but also PA. The inverse relation between age and PA is recognized, ${ }^{7}$ and estrogen deficiency is associated with the decrease in muscle mass and strength, ${ }^{21}$ which leads to physical capacity impairment. The differences observed among groups regarding BMI might have interfered with the results, as dissatisfaction with being overweight is associated with physical inactivity in elderly women. ${ }^{22}$ Furthermore, smoking rates were higher in the OP group and, paradoxically, among those with NBD. Smoking is associated with $\mathrm{OP}^{23}$ and it impairs physical fitness in general; ${ }^{24}$ thus, a higher rate of smokers is expected to be found in a sedentary group. However, in the NBD group (the more active one), the smoking rate was high, similar to the OP group. Moreover, factors such as bone pain and fractures, which would be expected to be more frequent in the OP group, could determine the ability to perform PA. However, none of the women had a history of pain or bone fractures.

This study has some limitations. As reported above, the findings indicate that the NBD group cannot be considered a proper control group, and that other factors besides bone density may have influenced the results. Furthermore, the number of participants was relatively small, and the use of questionnaires has been subject to criticism mainly regarding their reproducibility and validity, particularly when samples are limited. Nonetheless, questionnaires are useful and feasible tools from a logistic and economic standpoint, particularly in patients with some disabilities. ${ }^{25}$ Local studies using IPAQ have shown good reproducibility, particularly in women ${ }^{10,20}$ and elderly men. ${ }^{26}$ Their concurrent validity in elderly women has been considered moderate, ${ }^{10}$ and their use has been indicated when discrimination of the overall levels of PA suffices. ${ }^{26}$ On the other hand, this study, using the IPAQ, was able to establish the PA level among post-menopausal women with low BMD attending a specialized outpatient service. Determining the PA level is essential for creating proper routines regarding the amount, frequency and intensity of exercises, as well as for the development of intervention programs aiming to minimize and control problems such as function decline in the elderly. ${ }^{27}$

In conclusion, post-menopausal women with osteoporosis had higher rates of physical inactivity than those with osteopenia or NBD. Considering the role of physical exercise for bone health, strategies should be formulated to stimulate this group of patients to change their sedentary lifestyles.

\section{Conflict of Interests}

The authors declare that there is no conflict of interests regarding the publication of this paper.

\section{Acknowledgments}

The authors are grateful to the Brazilian National Council for Research and Development (CNPQ) and to the Coordination for the Improvement of University Researchers (Capes) for their financial support.

\section{References}

1 Costa AG, Wyman A, Siris ES, et al. When, where and how osteoporosis-associated fractures occur: an analysis from the Global Longitudinal Study of Osteoporosis in Women (GLOW). PLoS ONE 2013;8(12):1-6

2 Veiga Silva AC, da Rosa MI, Fernandes B, Lumertz S, Diniz RM, dos Reis Damiani ME. [Factors associated with osteopenia and osteoporosis in women undergoing bone mineral density test]. Rev Bras Reumatol 2015;55(3):223-228 Portuguese.

3 Compston J, Bowring C, Cooper A, et al; National Osteoporosis Guideline Group. Diagnosis and management of osteoporosis in postmenopausal women and older men in the UK: National 
Osteoporosis Guideline Group (NOGG) update 2013. Maturitas 2013;75(4):392-396

4 Cosman F, de Beur SJ, LeBoff MS, et al; National Osteoporosis Foundation. Clinician's guide to prevention and treatment of osteoporosis. Osteoporos Int 2014;25(10):2359-2381

5 Yuan Y, Chen X, Zhang L, et al. The roles of exercise in bone remodeling and in prevention and treatment of osteoporosis. Prog Biophys Mol Biol 2015; [Epub ahead of print]

6 Miko I, Szerb I, Szerb A, Poor G. Effectiveness of balance training programme in reducing the frequency of falling in established osteoporotic women: A randomized controlled trial. Clin Rehabil 2016; [Epub ahead of print]

7 Dumith SC, Hallal PC, Reis RS, Kohl HW III. Worldwide prevalence of physical inactivity and its association with human development index in 76 countries. Prev Med 2011;53(1-2):24-28

8 Viana JU, Silva SL, Torres JL, Dias JM, Pereira LS, Dias RC. Influence of sarcopenia and functionality indicators on the frailty profile of community-dwelling elderly subjects: a cross-sectional study. Braz J Phys Ther 2013;17(4):373-381

9 Matsudo S, Araújo T, Matsudo V, et al. [International physical activity questionnaire (IPAQ): study of validity and reability in Brazil]. Rev Bras Ativ Fís Saúde. 2001;6(2):5-18 Portuguese.

10 Dallanezi G, Corrente JE, Freire BF, Mazeto GMFS. [Concordance of the International Physical Activity Questionnaire with the pedometer, in postmenopausal women with osteoporosis]. . Rev Bras Clin Med 2011;9(2):93-96 Portuguese.

11 Pardini R, Matsudo S, Araújo T, et al. [Validation of the International Physical Activity Questionaire (IPAQ version 6): pilot study in Brazilian young adults]. Rev Bras Ciênc Mov. 2001;9(3): 45-51Portuguese.

12 Craig CL, Marshall AL, Sjöström M, et al. International physical activity questionnaire: 12-country reliability and validity. Med Sci Sports Exerc 2003;35(8):1381-1395

13 Dallanezi G, Nahas EA, Freire BF, Nahas-Neto J, Corrente JE, Mazeto GM. [Quality of life of women with low bone mass in postmenopause]. Rev Bras Ginecol Obstet 2011;33(3):133-138 Portuguese.

14 De Souza LB, Da Silva Mazeto GM, Bocchi SCM. Self-managing osteoporosis treatment for well-being recovery mediated by the (in)visibility of the disease signs. Rev Lat Am Enfermagem 2010; 18(3):398-405

15 Xu J, Lombardi G, Jiao W, Banfi G. Effects of exercise on bone status in female subjects, from young girls to postmenopausal women: an overview of systematic reviews and meta-analyses. Sports Med 2016; [Epub ahead of print]
16 Baretta E, Baretta M, Peres KG. [Physical activity and associated factors among adults in Joaçaba, Santa Catarina, Brazil]. Cad Saude Publica 2007;23(7):1595-1602 Portuguese.

17 Zaitune MP, Barros MB, César CL, Carandina L, Goldbaum M. [Variables associated with sedentary leisure time in the elderly in Campinas, São Paulo State, Brazil]. Cad Saude Publica 2007; 23(6):1329-1338 Portuguese.

18 Schöffl I, Kemmler W, Kladny B, Vonstengel S, Kalender WA Engelke K. In healthy elderly postmenopausal women variations in BMD and BMC at various skeletal sites are associated with differences in weight and lean body mass rather than by variations in habitual physical activity, strength or VO2max. J Musculoskelet Neuronal Interact 2008;8(4):363-374

19 Wee J, Sng BY, Shen L, Lim CT, Singh G, Das De S. The relationship between body mass index and physical activity levels in relation to bone mineral density in premenopausal and postmenopausal women. Arch Osteoporos 2013;8:162

20 Benedetti TB, Mazo GZ, Barros MVG. [Application of the International Physical Activity Questionnaire (IPAQ) for evaluation of elderly women: concurrent validity and test-retest reprodutibility]. Rev Bras. Ciênc. Mov. 2004;12(1):25-34 Portuguese.

21 Maltais ML, Desroches J, Dionne IJ. Changes in muscle mass and strength after menopause. J Musculoskelet Neuronal Interact 2009;9(4):186-197

22 Tribess S, Virtuoso-Júnior JS, Petroski EL. [Factors associated with physical inactivity amongst elderly women in low-income communities]. Rev Salud Publica (Bogota) 2009;11(1):39-49 Portuguese.

23 Baccaro LF, de Souza Santos Machado V, Costa-Paiva L, Sousa MH, Osis MJ, Pinto-Neto AM. Factors associated with osteoporosis in Brazilian women: a population-based household survey. Arch Osteoporos 2013;8:138

24 Ricci NA, Francisco CO, Rebelatto MN, Rebelatto JR. Influence of history of smoking on the physical capacity of older people. Arch Gerontol Geriatr 2011;52(1):79-83

25 Kasser SL, Jacobs JV, Littenberg B, Foley JT, Cardinal BJ, Maddalozzo GF. Exploring physical activity in women with multiple sclerosis: associations with fear of falling and underlying impairments. Am J Phys Med Rehabil 2014;93(6):461-469

26 Benedetti TRB, Antunes PC, Rodrigues-Añez CR, Mazo GZ, Petroski EL. Reproducibility and validity of the International Physical Activity Questionnaire (IPAQ) in elderly men. Rev Bras Med Esporte. 2007;13(1):11-16

27 Rabacow FM, Gomes MA, Marques P, Bonedetti TRB. [Questionnaires for measuring physical activity in the elderly]. Rev Bras Cineantropom Desempenho Hum. 2006;8(4):99-106 Portuguese. 